\title{
¿Y CUANDO SE QUIEBRA, ROMPE O FRAGMENTA EL AMOR?
}

DOI: https://doi.org/10.52039/seminarios.v62i217.123

Cecilio Raúl Berzosa*

Resulta iluminador realizar una relectura de Amoris laetitia desde las situaciones de los matrimonios que viven en continua disensión y enfrentamiento. O, con palabras de la propia exhortación, en su capítulo IV, «EI desafío de las crisis». Los escritos del Papa Francisco, al decir de la gente sencilla, tienen una ventaja: son claros y asequibles con su sola lectura. Por ello, nos limitamos a releer, parafrasear y comentar algunos de los números de esta exhortación que nos ayuden a distinguir mejor los retos y las propuestas.

\section{CUANDO LLEGA LA CRISIS}

Con realismo, en el número 232 se nos advierte que la historia de una familia está surcada por crisis de todo tipo. No deben asustarnos: forman parte de su dramática belleza. Ahora bien, ¿qué tenemos que hacer ante las crisis? Sin duda, no estancarnos en ellas, sino descubrir una «oportunidad» para ayudar a mejorar, a asentar y a madurar «el vino (amor) de la unión».

$Y$ todo ello desde un principio indiscutible: el matrimonio (y la familia) no es una convivencia "para ser cada vez menos felices», sino, al contrario, para aprender a ser felices de un modo nuevo. Por eso, cada crisis implica un aprendizaje que permite incrementar la intensidad de la vida compartida, o al menos encontrar un nuevo sentido a la experiencia matrimonial. De ningún modo hay que resignarse a una curva descendente, a un deterioro inevitable, a una soportable mediocridad. Al contrario, cuando el matrimonio se asume como una tarea, que implica también superar obstáculos, cada crisis se percibe como la ocasión para crecer. Y aunque la

* Mons. Raúl Berzosa es obispo de Ciudad Rodrigo. Ejerce la docencia en la Universidad Pontificia de Salamanca y está considerado un buen conocedor de la Teología del laicado. 
responsabilidad corresponde a los cónyuges, es bueno y necesario acompañarlos para que puedan aceptar y superar las crisis que lleguen.

Los matrimonios experimentados y formados deben acompañar a otros en este descubrimiento, para que las crisis no los asusten ni los lleven a tomar decisiones apresuradas.

En resumen: "Cada crisis esconde una buena noticia que hay que saber escuchar afinando el oído del corazón».

\section{Posturas o REACCIONES ANTE LAS CRISIS}

\section{a) La actitud «defensiva»}

Con el mismo realismo que en el número anterior, se nos advierte que la reacción inmediata ante el desafío de una crisis es ponerse a la defensiva, al sentir que escapa al propio control, y eso incomoda (n. 233). Estamos tentados a utilizar el recurso de negar los problemas, de esconderlos, de relativizar su importancia. Pero esta actitud, retrasa la solución y lleva a consumir mucha energía en un ocultamiento inútil que complicará todavía más las cosas. Cuando no se acepta la crisis, la convivencia se va deteriorando, a la vez que se va consolidando un aislamiento-individualismo que daña la intimidad y la convivencia. En la crisis no asumida, lo que sale más perjudicado es la comunicación. Y, poco a poco, alguien que era para uno «la persona que amo», pasa a ser, en un primer momento, «quien me acompaña siempre en la vida», y, luego, sólo «el padre o la madre de mis hijos», y al final, «un extraño».

\section{b) ¡Crear espacios de comunicación!}

Para enfrentar una crisis, se hace necesario «estar presentes», asumirla (n. 234). A veces las personas se aíslan para no manifestar lo que sienten o se arrinconan en el silencio mezquino y tramposo. Es necesario crear espacios para comunicarse de corazón a corazón. Pero esto no es nada fácil si nunca se aprendió a hacerlo. «Es todo un arte que se aprende en tiempos de calma, para ponerlo en práctica en los tiempos duros».

En dicha comunicación, hay que ayudar a descubrir las causas más ocultas de las crisis en los corazones de los cónyuges y a enfrentarlas, "como si fuera un parto que pasará y dejará un nuevo tesoro». Por desgracia, en situaciones difíciles o críticas la mayoría no acude a un acompañamiento pastoral, porque no lo siente acogedor, cercano, realista, y encarnado. 
¿Cómo acercarnos a las crisis matrimoniales con una mirada que no ignore su carga de dolor y de angustia? En la exhortación se nos dan algunas pautas que resumimos a continuación.

\section{LA VERDADERA MIRADA PASTORAL ANTE LAS CRISIS}

\section{a) Las crisis «normales o comunes» en la vida matrimonial y familiar}

En el número 235 se nos advierte que hay crisis comunes, que suelen ocurrir en todos los matrimonios, como la crisis de los comienzos, cuando hay que aprender a compatibilizar las diferencias y desprenderse de los padres; o la crisis de la llegada del hijo, con sus nuevos desafíos emocionales; la crisis de la crianza, que cambia los hábitos del matrimonio; la crisis de la adolescencia del hijo, que exige muchas energías, desestabiliza a los padres y a veces los enfrenta entre sí; la crisis del «nido vacío», que obliga a la pareja a mirarse nuevamente a sí misma; la crisis que se origina en la vejez de los padres de los cónyuges, que reclaman más presencia, cuidados y decisiones difíciles. Son situaciones exigentes pero comunes, que provocan miedos, sentimientos de culpa, depresiones o cansancios que pueden afectar gravemente a la unión, pero que son superables.

\section{b) Las crisis «personales»}

El número 236 nos habla de «las crisis personales», que inciden lógicamente en la pareja y que se relacionan con dificultades económicas, laborales, afectivas, sociales e incluso espirituales. A estas crisis se añaden circunstancias inesperadas que pueden alterar la vida familiar y que exigen un camino de perdón y reconciliación.

Mientras se intenta dar el paso del perdón, cada uno tiene que preguntarse, con serena humildad, si no ha creado él las condiciones para exponer al otro a cometer ciertos errores.

Algunas familias sucumben cuando los cónyuges se culpan mutuamente, pero la experiencia muestra que, con una ayuda adecuada y con la acción de reconciliación de la gracia de Dios, un gran porcentaje de crisis matrimoniales se superan de manera satisfactoria. Saber perdonar y sentirse perdonados constituye una experiencia fundamental en la vida familiar. «El difícil arte de la reconciliación, que requiere la ayuda de Dios, necesita de la generosa colaboración de familiares y amigos, y a veces incluso de ayuda externa y profesional». 


\section{c) Las crisis de la cultura ambiental}

Se nos advierte en el número 237 que en la cultura de hoy no pocos, cuando uno siente que no recibe lo que desea o no se cumple lo que soñaba, lo consideran razón suficiente para dar por finalizado su matrimonio. A veces, por desgracia, para decidir que todo acabó basta una insatisfacción, una ausencia en un momento en que se necesitaba al otro, un orgullo herido o un temor difuso. Se nos advierte que «hay situaciones propias de la inevitable fragilidad humana, a las cuales se otorga una carga emotiva demasiado grande». Por ejemplo, la sensación de no ser completamente correspondido, los celos, las diferencias que surgen entre los dos, el atractivo que despiertan otras personas, los nuevos intereses que tienden a apoderarse del corazón, los cambios físicos del cónyuge y tantas otras cosas. Pero todo ello, «más que atentados contra el amor, son oportunidades que invitan a recrearlo una vez más».

En esas circunstancias, algunos tienen la madurez necesaria para volver a elegir al otro como compañero de camino más allá de los límites de la relación, y aceptan con realismo que no pueda satisfacer todos los sueños acariciados (n. 238). Evitan considerarse los únicos mártires, valoran las pequeñas o limitadas posibilidades que les da la vida en familia y apuestan por fortalecer el vínculo en una construcción que llevará tiempo y esfuerzo. Porque en el fondo reconocen que cada crisis es como un nuevo «sí» que hace posible que el amor renazca fortalecido, transfigurado, madurado, iluminado.

En resumen, a partir de una crisis se tiene la valentía de buscar las raíces profundas de lo que está ocurriendo, de volver a negociar los acuerdos básicos, de encontrar un nuevo equilibrio y de caminar juntos una etapa nueva. Con esta actitud de constante apertura se pueden afrontar muchas situaciones difíciles.

d) Las crisis producidas por "viejas heridas», y que se remontan a la niñez y a la adolescencia

Hay muchas crisis cuando alguno de los miembros de la familia no ha madurado y no ha sanado heridas de alguna etapa de su vida (n. 239). La propia infancia o la adolescencia mal vividas son caldo de cultivo para crisis personales que terminan afectando al matrimonio. Si todos fueran personas que han madurado normalmente, las crisis serían menos frecuentes o menos dolorosas. Pero el hecho es que a veces las personas necesitan realizar a los cuarenta años una maduración atrasada que de- 
bería haberse logrado al final de la adolescencia. A veces se ama con un amor egocéntrico propio del niño, fijado en una etapa donde la realidad se distorsiona y se vive el capricho de que todo gire en torno al propio yo. Es un amor insaciable, que grita o llora cuando no tiene lo que desea. Otras veces se ama con un amor fijado en una etapa adolescente, marcado por la confrontación, la crítica ácida, el hábito de culpar a los otros, la lógica del sentimiento y de la fantasía, donde los demás deben llenar los propios vacíos o seguir los propios caprichos.

Muchos terminan su niñez sin haber sentido jamás que son amados incondicionalmente, y eso lastima su capacidad de confiar y de entregarse (n. 240). Una relación mal vivida con los propios padres y hermanos, que nunca ha sido sanada, reaparece y daña la vida conyugal. Entonces hay que hacer un proceso de liberación.

Cuando la relación entre los cónyuges no funciona bien, antes de tomar decisiones importantes conviene asegurarse de que cada uno haya hecho ese camino de curación de la propia historia. Eso exige reconocer la necesidad de sanar, pedir con insistencia la gracia de perdonar y de perdonarse, aceptar ayuda, buscar motivaciones positivas y volver a intentarlo una y otra vez. Cada uno tiene que ser muy sincero consigo mismo para reconocer que su modo de vivir el amor tiene estas inmadureces: "Por más que parezca evidente que toda la culpa es del otro, nunca es posible superar una crisis esperando que sólo cambie el otro». También hay que preguntarse por las cosas que uno mismo podría madurar o sanar para favorecer la superación del conflicto.

\section{ACOMPAÑAR DESPUÉS DE LAS RUPTURAS Y DIVORCIOS}

\section{a) Cuando la ruptura es inevitable}

Es cierto que, ante todo, hay que tratar de superar las crisis con los criterios antes enunciados. Sin embargo, en el número 241 de Amoris laetitia se nos advierte, con realismo y a la vez con dolor, que en algunos casos la valoración de la dignidad propia y del bien de los hijos exige poner un límite firme a las pretensiones excesivas del otro, a una gran injusticia, a la violencia o a una falta de respeto que se ha vuelto crónica. Hay que reconocer que «existen casos donde la separación es inevitable. A veces puede llegar a ser incluso moralmente necesaria, cuando precisamente se trata de sustraer al cónyuge más débil, o a los hijos pequeños, de las heridas más graves causadas por la prepotencia y la violencia, el desaliento 
y la explotación, la ajenidad y la indiferencia». Ahora bien, siempre «debe considerarse como un remedio extremo, después de que cualquier intento razonable haya sido inútil».

b) Acompañar pastoralmente a los separados, divorciados y abandonados

El número 242, es claro: «Hay que acoger y valorar especialmente el dolor de quienes han sufrido injustamente la separación, el divorcio o el abandono, o bien se han visto obligados a romper la convivencia por los maltratos del cónyuge».

El perdón por la injusticia sufrida no es fácil, pero es un camino que la gracia hace posible. De ahí la necesidad de una pastoral de la reconciliación y de la mediación, a través de centros de escucha especializados que habría que establecer en las diócesis. ¿Cómo orientar estos casos? Vamos por partes.

1. Acompañar a los divorciados que no se han vuelto a casar. Sigue insistiendo el número 242 que hay que alentar a las personas divorciadas que no se han vuelto a casar -que a menudo son testigos de la fidelidad matrimonial-a encontrar en la eucaristía el alimento que las sostenga en su estado. La comunidad local y los pastores deben acompañar a estas personas con solicitud, sobre todo cuando hay hijos o su situación de pobreza es grave. Un fracaso familiar se vuelve mucho más traumático y doloroso cuando hay pobreza, porque hay muchos menos recursos para reorientar la existencia. Una persona pobre que pierde el ámbito de la tutela de la familia queda doblemente expuesta al abandono y a todo tipo de riesgos para su integridad.

2. Ante los divorciados que viven una nueva unión. En relación a las personas divorciadas que viven en nueva unión, el número 243 subraya que es importante hacerles sentir que son parte de la Iglesia, que «no están excomulgadas» y que no son tratadas como tales, porque siempre forman parte de la comunión eclesial. No se puede decir ni más alto ni más claro: «Estas situaciones exigen un atento discernimiento y un acompañamiento con gran respeto, evitando todo lenguaje y actitud que las haga sentir discriminadas, y promoviendo su participación en la vida de la comunidad. Para la comunidad cristiana, hacerse cargo de ellos no implica un debilitamiento de su fe y de su testimonio acerca de la indisolubilidad matrimonial, es más, en ese cuidado expresa precisamente su caridad» (n. 243). 
Por otra parte, un gran número de Padres sinodales «subrayó la necesidad de hacer más accesibles y ágiles, posiblemente totalmente gratuitos, los procedimientos para el reconocimiento de los casos de nulidad» (n. 244). La lentitud de los procesos irrita y cansa a la gente. Por eso el Papa Francisco ha promulgado dos recientes documentos sobre esta materia para ayudar a la simplificación de los procedimientos de declaración de nulidad matrimonial. A través de ellos el Papa ha querido «hacer evidente que el mismo Obispo en su Iglesia, de la que es constituido pastor y cabeza, es por eso mismo juez entre los fieles que se le han confiado». Por ello, la aplicación de estos documentos es una gran responsabilidad para los Ordinarios diocesanos, llamados a juzgar ellos mismos algunas causas y a garantizar, en todos los modos, un acceso más fácil de los fieles a la justicia. Esto implica la preparación de un número suficiente de personal, integrado por clérigos y laicos, que se dedique de modo prioritario a este servicio eclesial. Así pues, será necesario poner a disposición de las personas separadas y de las parejas en crisis un servicio de información, consejo y mediación, vinculado a la pastoral familiar.

3. Cuando los hijos son las víctimas inocentes. Los Padres sinodales también destacaron las consecuencias de la separación o del divorcio sobre los hijos, en cualquier caso víctimas inocentes de la situación. Los hijos son la primera preocupación y «jamás se deben tomar a los hijos como rehenes» (n. 245); que no sean los hijos quienes «carguen con el peso de la separación, y que no sean usados como rehenes o armas arrojadizas contra el otro cónyuge». "Que crezcan escuchando que mamá habla bien del papá, aunque no estén juntos, y que papá habla bien de mamá». Es una irresponsabilidad dañar la imagen del padre o de la madre con el objeto de acaparar el afecto del hijo, para vengarse o para defenderse, porque eso afectará a la vida interior de ese niño y provocará heridas difíciles de sanar.

La Iglesia, aunque comprende las situaciones conflictivas que atraviesan los matrimonios, no puede dejar de ser voz de los más frágiles, que son los hijos que sufren, muchas veces en silencio (n. 246). Hoy, a pesar de nuestra sensibilidad aparentemente evolucionada, y todos nuestros refinados análisis psicológicos, el Papa Francisco se pregunta si no nos hemos anestesiado también respecto a las heridas del alma de los niños... «¿Sentimos el peso de la montaña que aplasta el alma de un niño?». Las malas experiencias no ayudan a que los niños maduren para ser capaces de compromisos definitivos. 
4. Las comunidades cristianas no pueden abandonar a los divorciados. Se insiste, en el número 246 en que las comunidades cristianas no deben dejar solos a los padres divorciados en una nueva unión. Al contrario, deben incluirlos y acompañarlos en su función educativa. Porque «¿cómo podremos recomendar a estos padres que hagan todo lo posible para educar a sus hijos en la vida cristiana, dándoles el ejemplo de una fe convencida y practicada, si los tuviésemos alejados de la vida en comunidad, como si estuviesen excomulgados? Se debe obrar de tal forma que no se sumen otros pesos además de los que los hijos, en estas situaciones, ya tienen que cargar». Ayudar a sanar las heridas de los padres y ayudarlos espiritualmente es un bien también para los hijos, quienes necesitan el rostro familiar de la Iglesia que los apoye en esta experiencia traumática.

Una conclusión se impone: Ciertamente, el divorcio es un mal, y es muy preocupante el crecimiento del número de divorcios. Sin duda, nuestra tarea pastoral más importante con respecto a las familias es fortalecer el amor y ayudar a sanar las heridas, de manera que podamos prevenir el avance de este drama de nuestra época (n. 246).

\section{ANTE LAS UNIONES DE MATRIMONIOS CIVILES Y ANTE LAS SIMPLES UNIONES}

Hemos titulado esta reflexión, "cuando se quiebra o rompe (separaciones / divorcios) o se fragmenta el amor». Hablamos ahora de los matrimonios «no completos entre bautizados. Los que denominamos «uniones civiles» y meras uniones. La exhortación Amoris laetitia lo aborda en el capítulo VIII, el más citado por los comentaristas, y el más «polémico».

\section{a) Llamada a discernir el "porqué» de los matrimonios civiles y de las simples uniones}

En el número 294, se afirma, de entrada, que «la elección del matrimonio civil o, en otros casos, de la simple convivencia, frecuentemente no está motivada por prejuicios o resistencias a la unión sacramental, sino por situaciones culturales o contingentes». En estas situaciones podrán ser valorados aquellos signos de amor que de algún modo reflejan el amor de Dios.

Sabemos que «crece continuamente el número de quienes después de haber vivido juntos durante largo tiempo piden la celebración del matrimonio en la Iglesia. La simple convivencia a menudo se elige a causa 
de la mentalidad general contraria a las instituciones y a los compromisos definitivos, pero también porque se espera adquirir una mayor seguridad existencial (ejemplo, trabajo y salario fijo).

En otros países, por otra parte, las uniones de hecho son muy numerosas, no sólo por el rechazo de los valores de la familia y del matrimonio, sino sobre todo por el hecho de que casarse se considera un lujo por las condiciones sociales, de modo que la miseria material impulsa a vivir uniones de hecho. Es preciso afrontar todas estas situaciones de manera constructiva, tratando de transformarlas como oportunidad hacia la plenitud del matrimonio y de la familia a la luz del Evangelio. Se trata de acogerlas y acompañarlas con paciencia y delicadeza». Es lo que hizo Jesús, por ejemplo, con la samaritana (Jn 4, 1-26).

\section{b) Aplicar sanamente la «ley de la gradualidad pastoral»}

El número 295, es muy interesante y clave en la pastoral familiar en relación a las Ilamadas «situaciones irregulares». Se remite a san Juan Pablo II, quien proponía la llamada «ley de gradualidad» o conciencia de que el ser humano «conoce, ama y realiza el bien moral según diversas etapas de crecimiento». No es una "gradualidad de la ley misma», sino una gradualidad en el ejercicio de los actos libres en sujetos que no están en condiciones de comprender, de valorar o de practicar plenamente las exigencias objetivas de la ley. Porque cada ser humano «avanza gradualmente con la progresiva integración de los dones de Dios y de las exigencias de su amor definitivo y absoluto en toda la vida personal y social».

En cualquier caso, para que no quede duda acerca del modo de tratar las diversas situaciones llamadas «irregulares», los Padres sinodales alcanzaron un consenso general: «Respecto a un enfoque pastoral dirigido a las personas que han contraído matrimonio civil, que son divorciados y vueltos a casar, o que simplemente conviven, compete a la Iglesia revelarles la divina pedagogía de la gracia en sus vidas y ayudarles a alcanzar la plenitud del designio que Dios tiene para ellos; es posible con la fuerza del Espíritu Santo» (n. 297).

\section{c) Siempre reintegrar, nunca marginar}

Dos lógicas recorren la larga historia de la Iglesia: marginar y reintegrar (n. 296). «El camino de la Iglesia es el de no condenar a nadie para siempre y difundir la misericordia de Dios a todas las personas que la piden con corazón sincero. Porque la caridad verdadera siempre es inmerecida, 
incondicional y gratuita». Hay que evitar los juicios que no toman en cuenta la complejidad de las diversas situaciones, y hay que estar atentos al modo en que las personas viven y sufren a causa de su condición.

El número 297 insiste en que se trata de integrar a todos y en que se debe ayudar a cada uno a encontrar su propia manera de participar en la comunidad eclesial, de modo que se sienta objeto de una misericordia inmerecida, incondicional y gratuita. Nadie puede ser condenado para siempre, porque esa no es la lógica del Evangelio. "No se refiere la exhortación sólo a los divorciados en nueva unión, sino a todos en cualquier situación en que se encuentren». Obviamente, si alguien ostenta un pecado objetivo como si fuese parte del ideal cristiano o quiere imponer algo diferente a lo que enseña la Iglesia, no puede pretender dar catequesis o predicar, y en ese sentido hay algo que lo separa de la comunidad (Mt $18,17)$. Necesita volver a escuchar el anuncio del Evangelio y la invitación a la conversión. Pero aun para él, puede haber alguna manera de participar en la vida de la comunidad, ya sea en tareas sociales, en reuniones de oración o de la manera que sugiera su propia iniciativa, junto con el discernimiento del pastor.

d) Una vez más, sobre los divorciados y sus «diversas realidades existenciales»

El número 298 retorna sobre los divorciados en nueva unión. Pueden encontrarse en situaciones muy diferentes, por lo que «no han de ser catalogados o encerrados en afirmaciones demasiado rígidas sin dejar lugar a un adecuado discernimiento personal y pastoral».

Por ejemplo, existe el caso de una segunda unión consolidada en el tiempo, con nuevos hijos, con probada fidelidad, con entrega generosa y compromiso cristiano, con conocimiento de la irregularidad de su situación y con gran dificultad para volver atrás sin sentir en conciencia que se cae en nuevas culpas (n. 298).

También está el caso de los que hicieron grandes esfuerzos para salvar el primer matrimonio y aun así sufrieron un abandono injusto, o el de «los que han contraído una segunda unión en vista a la educación de los hijos, y a veces están subjetivamente seguros en conciencia de que el precedente matrimonio, irreparablemente destruido, no había sido nunca válido» (n. 298).

Pero otra cosa es una nueva unión que viene de un reciente divorcio, con todas las consecuencias de sufrimiento y de confusión que afectan a 
los hijos y a familias enteras, o la situación de alguien que reiteradamente ha fallado a sus compromisos familiares. Debe quedar claro que este no es el ideal que el Evangelio propone para el matrimonio y la familia. Los Padres sinodales han expresado que el discernimiento de los pastores siempre debe hacerse "distinguiendo adecuadamente», con una mirada que «discierna bien las situaciones» y sabiendo que no existen «recetas sencillas» (n. 298).

\section{e) A favor de una integración mayor de los divorciados en la comunidad cristiana}

En el número 299 el Papa Francisco afirma: «Acojo las consideraciones de muchos Padres sinodales, quienes quisieron expresar que los bautizados que se han divorciado y se han vuelto a casar civilmente deben ser más integrados en la comunidad cristiana en las diversas formas posibles, evitando cualquier ocasión de escándalo».

La lógica de la integración es la clave de su acompañamiento pastoral, para que no sólo sepan que pertenecen al Cuerpo de Cristo que es la Iglesia, sino que puedan tener una experiencia feliz y fecunda. Son bautizados, son hermanos y hermanas, y el Espíritu Santo derrama en ellos dones y carismas para el bien de todos. Su participación puede expresarse en diferentes servicios eclesiales; es necesario, por ello, discernir cuáles de las diversas formas de exclusión actualmente practicadas en el ámbito litúrgico, pastoral, educativo e institucional pueden ser superadas. Ellos no sólo no tienen que sentirse excomulgados, sino que pueden vivir y madurar como miembros vivos de la Iglesia, sintiéndola como una madre que les acoge siempre, los cuida con afecto y los anima en el camino de la vida y del Evangelio. Esta integración, se repite de nuevo, es también necesaria para el cuidado y la educación cristiana de sus hijos, que deben ser considerados los más importantes.

\section{f) No puede existir «normativa general canónica para todos los casos»}

El número 300 advierte con sano realismo que «si se tiene en cuenta la innumerable diversidad de situaciones concretas puede comprenderse que no debía esperarse del Sínodo o de esta exhortación una nueva normativa general de tipo canónico, aplicable a todos los casos». Sólo cabe un nuevo aliento a un responsable discernimiento personal y pastoral de los casos particulares, que debería reconocer que, puesto que «el grado de responsabilidad no es igual en todos los casos, las consecuencias o 
efectos de una norma no necesariamente deben ser siempre los mismos». Los presbíteros tienen la tarea de acompañar a las personas interesadas en el camino del discernimiento, de acuerdo a la enseñanza de la Iglesia y las orientaciones del Obispo.

En este proceso será útil hacer un examen de conciencia de los momentos de reflexión y de arrepentimiento. Los divorciados vueltos a casar deberían preguntarse cómo se han comportado con sus hijos cuando la unión conyugal entró en crisis; si hubo intentos de reconciliación; cómo es la situación del cónyuge abandonado; qué consecuencias tiene la nueva relación sobre el resto de la familia y la comunidad de los fieles; qué ejemplo ofrece esa relación a los jóvenes que deben prepararse al matrimonio. Una reflexión sincera puede fortalecer la confianza en la misericordia de Dios, que no es negada a nadie. "Se trata de un itinerario de acompañamiento y de discernimiento que orienta a estos fieles a la toma de conciencia de su situación ante Dios. Dado que en la misma ley no hay gradualidad (Familiaris consortio, 34), este discernimiento no podrá jamás prescindir de las exigencias de verdad y de caridad del Evangelio propuesto por la Iglesia. Para que esto suceda, deben garantizarse las condiciones necesarias de humildad, reserva, amor a la Iglesia y a su enseñanza, en la búsqueda sincera de la voluntad de Dios y con el deseo de alcanzar una respuesta a ella más perfecta».

Estas actitudes, que pide el Papa Francisco, resultan fundamentales para evitar el grave riesgo de mensajes equivocados, como la idea de que algún sacerdote puede conceder rápidamente "excepciones», o la idea de que existen personas que pueden obtener privilegios sacramentales a cambio de favores.

\section{g) Circunstancias «atenuantes» en el discernimiento pastoral}

El número 301 habla de las circunstancias «atenuantes» en las «situaciones irregulares»; que no es lo mismo que pretender disminuir las exigencias del Evangelio. Ya no resulta posible decir que todas las personas que se encuentran en alguna situación «irregular» viven en una situación de «pecado mortal», privadas de la gracia santificante. Los límites no tienen que ver solamente con un eventual desconocimiento de la norma, sino que una persona, aun conociendo bien dicha norma, puede tener una gran dificultad para comprenderla, o puede estar en condiciones concretas que no le permiten obrar de manera diferente y tomar otras decisiones sin una nueva culpa. En resumen, y como expresaron los Padres sino- 
dales, "puede haber factores que limitan la capacidad de decisión». Ya santo Tomás de Aquino lo reconocía, y el Catecismo de la Iglesia Católica se expresa de una manera contundente: "La imputabilidad y la responsabilidad de una acción pueden quedar disminuidas e incluso suprimidas a causa de la ignorancia, la inadvertencia, la violencia, el temor, los hábitos, los afectos desordenados [...] la inmadurez afectiva, la fuerza de los hábitos contraídos, el estado de angustia u otros factores psíquicos o sociales». Por esta razón, un juicio negativo sobre una situación objetiva no implica un juicio sobre la imputabilidad o la culpabilidad de la persona involucrada (n. 302).

Desde lo expresado anteriormente, y en relación a la praxis de la Iglesia en algunas situaciones que no realizan objetivamente su concepción del matrimonio, hay que alentar, por un lado, la maduración hacia una conciencia iluminada, formada y acompañada por el discernimiento responsable y riguroso del pastor, además de proponer una confianza cada vez mayor en la gracia; pero, por otro, esa misma conciencia puede reconocer no sólo que una situación no responde objetivamente a la propuesta general del Evangelio, sino que también puede reconocer, con sinceridad y honestidad, aquello que por ahora es la respuesta generosa que se puede ofrecer a Dios, y descubrir con cierta seguridad moral que esa es la entrega que Dios mismo está reclamando en medio de la complejidad concreta de los límites, aunque todavía no sea de una manera plena el ideal objetivo.

De todos modos, recordemos que este discernimiento es dinámico y que debe permanecer siempre abierto a nuevas etapas de crecimiento y a nuevas decisiones que permitan realizar el ideal de una manera más plena (n. 303).

\section{h) Cómo aplicar las normas en un sano discernimiento}

El número 304 afirma que «es mezquino detenerse sólo a considerar si el obrar de una persona responde o no a una ley o norma general, porque eso no basta para discernir y asegurar una plena fidelidad a Dios en la existencia concreta de un ser humano». Hay que recordar siempre lo que enseñaba santo Tomás de Aquino: «Aunque en los principios generales haya necesidad, cuanto más se afrontan las cosas particulares, tanta más indeterminación hay [...] En el ámbito de la acción, la verdad o la rectitud práctica no son lo mismo en todas las aplicaciones particulares, sino solamente en los principios generales; y en aquellos para los cuales 
la rectitud es idéntica en las propias acciones, esta no es igualmente conocida por todos [...] Cuanto más se desciende a lo particular, tanto más aumenta la indeterminación».

Es verdad que las normas generales presentan un bien que nunca se debe desatender ni descuidar, pero en su formulación no pueden abarcar absolutamente todas las situaciones particulares. Al mismo tiempo, hay que decir que, precisamente por esa razón, aquello que forma parte de un discernimiento práctico ante una situación particular no puede ser elevado a la categoría de una norma. Ello no sólo daría lugar a una casuística insoportable, sino que pondría en riesgo los valores que se deben preservar con especial cuidado.

Por ello, un pastor no puede sentirse satisfecho sólo aplicando leyes morales a quienes viven en situaciones «irregulares», como si fueran piedras que se lanzan contra la vida de las personas (n. 305). A causa de los condicionamientos o factores atenuantes, es posible que, en medio de una situación objetiva de pecado -que no sea subjetivamente culpable o que no lo sea de modo pleno-, se pueda vivir en gracia de Dios, se pueda amar y se pueda crecer en la vida de la gracia y la caridad, recibiendo para ello la ayuda de la Iglesia. El discernimiento debe ayudar a encontrar los posibles caminos de respuesta a Dios y de crecimiento en medio de los límites.

Se insiste en que «por creer que todo es blanco o negro a veces cerramos el camino de la gracia y del crecimiento, y desalentamos caminos de santificación que dan gloria a Dios» (n. 305). Recordemos que «un pequeño paso, en medio de grandes límites humanos, puede ser más agradable a Dios que la vida exteriormente correcta de quien transcurre sus días sin enfrentar importantes dificultades». La pastoral concreta de los ministros y de las comunidades no puede dejar de incorporar esta realidad.

\section{i) Por encima de todo, la caridad cristiana}

En cualquier circunstancia, ante quienes tengan dificultades para vivir plenamente la ley divina, debe resonar la invitación a recorrer la via caritatis (n. 306). La caridad fraterna es la primera ley de los cristianos (Jn 15, 12; Gal 5, 14). Es también lo que enseña san Agustín: «Así como en peligro de incendio correríamos a buscar agua para apagarlo, [...] del mismo modo, si de nuestra paja surgiera la llama del pecado, y por eso nos turbamos, cuando se nos ofrezca la ocasión de una obra llena de misericordia, alegrémonos de ella como si fuera una fuente que se nos ofrezca en la que podamos sofocar el incendio» (n. 306). 
j) ¡Y la lógica de la misericordia pastoral!

Es cierto, se nos advierte en el número 307 , que para evitar cualquier interpretación desviada, hay que recordar que la Iglesia nunca debe renunciar a proponer el ideal pleno del matrimonio, es decir, el proyecto de Dios en toda su grandeza; la tibieza, cualquier forma de relativismo, o un excesivo respeto a la hora de proponerlo, serían una falta de fidelidad al Evangelio y también una falta de amor de la Iglesia hacia los mismos jóvenes. Comprender las situaciones excepcionales nunca implica ocultar la luz del ideal más pleno ni proponer menos que lo que Jesús ofrece al ser humano. «Hoy, más importante que una pastoral de los fracasos es el esfuerzo pastoral para consolidar los matrimonios y así prevenir las rupturas» (n. 307).

Pero de nuestra conciencia del peso de las circunstancias atenuantes -psicológicas, históricas e incluso biológicas- se sigue que, «sin disminuir el valor del ideal evangélico, hay que acompañar con misericordia y paciencia las etapas posibles de crecimiento de las personas que se van construyendo día a día», dando lugar a «la misericordia del Señor que nos estimula a hacer el bien posible» (n. 308).

El Papa Francisco comprende a quienes prefieren una pastoral más rígida y que no dé lugar a confusión alguna. Pero cree sinceramente que Jesucristo quiere «una Iglesia atenta al bien que el Espíritu derrama en medio de la fragilidad», porque la Iglesia es una Madre que, al mismo tiempo que expresa claramente su enseñanza objetiva, «no renuncia al bien posible, aunque corra el riesgo de mancharse con el barro del camino» (n. 308).

En este sentido, los pastores que proponen a los fieles el ideal pleno del Evangelio y la doctrina de la Iglesia, deben ayudarles también a asumir la lógica de la compasión con los frágiles y a evitar persecuciones o juicios demasiado duros o impacientes. El mismo Evangelio nos reclama que no juzguemos ni condenemos (Mt 7, 1; Lc 6, 37).

\section{Palabras finales: todo ello, jen el AÑo de la Misericordia!}

No es posible concluir mejor nuestra relectura de Amoris laetitia que con su número 309 , donde se afirma que es providencial que estas reflexiones se desarrollen en el contexto de un Año jubilar dedicado a la misericordia, porque también frente a las más diversas situaciones que afectan a la familia, «la Iglesia tiene la misión de anunciar la misericordia de Dios, corazón palpitante del Evangelio, que por su medio debe alcanzar 
la mente y el corazón de toda persona. La Esposa de Cristo hace suyo el comportamiento del Hijo de Dios que sale a encontrar a todos, sin excluir a ninguno».

Concluye el Papa Francisco con un broche de oro, brillante y profundamente realista: La Iglesia «sabe bien que Jesús mismo se presenta como Pastor de cien ovejas, no de noventa y nueve. Las quiere todas. A partir de esta consciencia, se hará posible que a todos, creyentes y lejanos, pueda llegar el bálsamo de la misericordia como signo del Reino de Dios que está ya presente en medio de nosotros».

Todo un reto y una esperanza, llamados a hacerlo realidad, particularmente en los matrimonios donde el amor se ha quebrado, roto o fragmentado, como rezaba el título de la presente reflexión. 